\title{
A Reply to the Critique of Job Market Reality for Postsecondary Graduates
}

\author{
ZOLTAN ZSIGMOND*
}

I wholeheartedly welcome the criticism of Dr. Laura Selleck of the Council of Ontario Universities Research Division. She has obviously spent a great deal of time reading our report, Job Market Reality for Postsecondary Graduates. However, by focusing on discrepancies and inconsistencies, she seems to have missed the key results of the survey. Thus, I will first briefly review our findings. Next, I will acknowledge what, with hindsight, I can see are shortcomings in the study. Then I will reply to Dr. Selleck's criticism.

\section{Results of the Survey}

Job Market Reality makes several major points about labour market conditions for recent graduates:

1. As the crest of the baby boom generation enters the labour force, a mismatch has developed between the supply of postsecondary graduates and demand for their skills.

2. Graduates with employment-oriented training by and large have more early success than those with a general education.

3. The traditional high status white-collar jobs (in education and government), which postsecondary graduates used to obtain with relative ease, are not increasing quickly enough to keep up with the supply of graduates.

4. Unemployment is not the major problem facing postsecondary graduates. In fact, with more education, it is easier for an individual to find a job. Data in the study show that young people without postsecondary credentials have much higher unemployment rates than their contemporaries with diplomas or degrees.

5. Underemployment - the quality of those jobs - is the issue today. A growing number of graduates are chasing an insufficient number of desirable positions. Blocked out of the top jobs, which are taken by those with specialized training or postgraduate degrees, many postsecondary graduates are applying for positions that in the past would have been filled by high school graduates.

6. In all respects, female graduates have less job market success than their male counterparts.

7. The graduates' situation explained in Job Market Reality is unlikely to improve in the near future. Although the statistics are now at least three years old,

*Education Division Statistics Canada 
I believe the message is valid today and will still be valid tomorrow. Education statistics show that the current distribution of postsecondary enrolment by field of study is not markedly different from the distribution of degrees and diplomas granted in 1976. (The only noticeable change is a shift toward business and engineering.) More than half the 330,000 undergraduates enrolled full-time in Canada's universities for the $1979-80$ academic year were in arts, general science or education programs.

Two major factors have produced the present situation. Either of these factors would have created a job squeeze, but the coincidence has resulted in severe employment problems. The factors are: 1) demographic trends and 2) economic conditions. There is little likelihood of improvement in the immediate future:

- Demographic data contain no suggestion of a second baby boom that would significantly increase the need for teachers and thereby improve employment prospects for many graduates.

- Economic data give no indication that inflation-related problems will diminish, so governments are apt to continue to restrict expenditures and hiring. This is crucial for postsecondary graduates, since a large percentage of them have customarily found public sector employment (including teaching).

The major problem today is not in the education system, but in the labour market which cannot create enough jobs traditionally requiring postsecondary education.

All these points were brought out in Job Market Reality, but I admit that the presentation was disjointed, and they were not easy to find.

\section{Shortcomings of the Report}

Job Market Reality has many flaws, not the least of which is its length -500 pages. But this is, in fact, a trimmed-down version of the original which contained about 500 pages of tables and more than 300 pages of text. When we began cutting, we usually chose to eliminate commentary and preserve the tabular data.

This created another problem, namely, the publication's inconvenient layout. We do not devote a separate chapter to a comprehensive treatment of the overall picture. Instead, comments, analyses, observations and conclusions are usually placed next to the appropriate tables. This form of organization may be satisfactory for readers who are interested in the outcomes for only one or two fields of study. They can turn to the table and read the accompanying text. But it might not be easy for a general reviewer to grasp the content of the entire publication.

For example, Dr. Selleck observes:

Students, educational institutions, and governments are urged to make adjustments in order to avoid the mismatches apparently so detrimental to the survey class of 1976 . Unfortunately, if they were to use Job Market Reality as their major guide, it is very likely that graduates from certain programs would quickly exceed the supply of appropriate jobs, since commentary on the data seems to be weighed in favour of job-oriented education. 
But in Section III - Overview, we make that very point:

It appears, then, that the sheer size of the graduating class, at least in programs not geared to specific occupations, intensifies competition in a job market where general degrees are not in great demand. This may contribute to unemployment, underemployment, and the problem of unrelated jobs, particularly during the transition period between education and career.

Yet the problem cannot be solved by simply suggesting that students should enrol in the more occupation-oriented programs. Given the large numbers, this would quickly lead to a mismatch between the supply of graduates in particular disciplines and available jobs. (This is not to suggest that some adjustment is not possible). (page 52)

The main weakness of the report, however, is that it does not mark the beginning of a time series. We acknowledge this in the text:

The most serious limitation of the survey is that it was a onetime effort. Unlike the United States, where a comparable study is conducted every two years, Canada's National Postsecondary Graduates Survey of 1978 is the only source of nationwide data about labour market outcomes for postsecondary graduates. To establish a time series, a similar exercise, undertaken regularly, is highly desirable. A continuing survey would greatly assist in the projection of labour market supply and demand, and would help those entering postsecondary institutions to make an informed choice of program. (page 40)

\section{A Reply to the Critique}

\section{Highlights}

The critique begins with an examination of the seven-page Summary and Highlights, the tenor of which is considered inappropriate.

But it is the nature of highlights to be short and sharp. No one can expect them to include all the "ifs" and "buts," and page references after each highlight enable readers to get a fuller explanation.

I do not consider the language "dramatic," but we did try to make the text more readable than many Statistics Canada reports.

The review notes: "Individual highlights tend to emphasize problems." Of course. This was one of the main purposes of the survey - to discover the problems encountered in the labour market by postsecondary graduates of different fields. Positive and negative results are reported for graduates of both universities and colleges. It is true that the highlights mention very few exceptions to the general findings, but we do point out which fields of study did well. And we observe that philosophy graduates with bachelor's degrees tended to be satisfied with relatively low pay. It could be argued that, since this group accounted for just $0.7 \%$ of university graduates, they did not belong in the highlights.

We are quoted as saying: "About a third of the university graduates were in the occupations which received the least favourable assessment, including 
clerical, sales and similar low-paid jobs." (page 12) This, it is noted, includes $24.3 \%$ of graduates in "other occupations," some of which were "entirely suitable," for example university teaching and journalism. We should have been more explicit and pointed out that about 60\% (the majority) of these "other occupations" were also clerical, sales, or blue-collar jobs. Furthermore, we could have looked only at the bachelor's degree recipients rather than university graduates as a whole, because most of the "entirely suitable" occupations were held by master's or Ph.D. graduates.

It is also true that the highlights do not stress that the comparative trade salary data refer to all workers. Nonetheless, the page reference is given, and more important, that table is itself confirmation of our statement that many trades pay better than some occupations held by postsecondary graduates. For instance, pipe fitters and welders were averaging $\$ 17,600$ and $\$ 16,900$, respectively, versus $\$ 16,500$ for physiotherapists, $\$ 15,500$ for general duty nurses and $\$ 12,700$ for medical laboratory technicians.

But the chief complaint is that "commentary on the data seems to be weighed in favour of job-oriented education." It is suggested that we chose to remark on findings that reinforce our bias: "Beginning with the summary and highlights it is difficult to avoid the impression that data are selected for specific mention in order to support this view, and other data are ignored if they tend to contradict it." We were, however, somewhat constrained by the results of the survey. No matter how the numbers are twisted and turned, the graduates themselves are overwhelmingly in favour of job-oriented education. Naturally, there are exceptions, but these do not change the general findings. Because of these exceptions, as noted above, readers are always referred to more detailed data. That the reader will not go beyond the highlights is only the reviewer's assumption. Probability is high that anyone really interested in outcomes for particular fields would look at the full commentary and tables.

The concern is that potential postsecondary students might base their educational plans on Job Market Reality alone. We never intended that the report be secondary students' main decision-making tool when they contemplate further education. However, as we say early in the report, "The primary goal is to help senior secondary students who are considering career choices and options for further study. The object is not to offer advice, but to present a realistic perspective of job market opportunities." (page 37). We go on to point out that the study's value lies in the comparisons of outcomes for graduates of different fields.

Students may be interested in comparing occupational categories, salaries, and particularly, the graduates' own assessment of their career development. Awareness of earlier graduates' frustrations and regrets might help them avoid similar disappointments. ... The great variety of disciplines and occupations is a substantial basis for comparison. (page 37)

It seems the reviewer would prefer that we downplay the favourable outcomes for job-related disciplines and put more emphasis on positive aspects of less 
job-related fields. In my opinion, this would be a misinterpretation of the data and would mislead readers. There is no getting around it - graduates with practical skills that were in short supply had the greatest labour market success.

\section{Ranking of Fields}

The deficiencies of the rank order section are seen to be:

1. The variables are not statistically correlated, and only broad comparisons are made.

2. There are exceptions to the general conclusions.

3. It implies that all programs are directly comparable, regardless of level or entrance requirements.

4. The salary data for the top $10 \%$ of each field show that the most successful (in terms of salary) arts and science graduates compare favourably with graduates of more vocationally-oriented university programs.

5. No conclusive evidence is provided in the report to justify the statement: "Thus, the message of most graduates after two years of coping with the work world is plain; at universities as well as in colleges, they want jobrelated programs that match the needs of the labour market (page 153)"

Each of these points can be answered:

1. Would statistical correlations make the report more comprehensible, and therefore more useful, to students? The text explains why only broad comparisons are made:

Some caution is required in interpreting these tables. The numerical rank does not mean that a particular field is "worse" than the previous ones. It simply means that at the time of the survey, graduates of that field stood a few points higher or lower on a certain variable than some others. Because these relative positions are changing constantly, a more useful approach is to divide a table into several parts, for example, thirds - the top, the middle, and the bottom. With such a division, general patterns emerge. If a field is close to the top or above average for that type of diploma or degree on one list, chances are that it will rank high on others, and vice versa. For instance, in a field characterized by high underemployment (negative), relative salaries are apt to be below average. (pages 121-122)

2. Of course, there are exceptions, but those do not change the general findings.

3. The rank order tables do not imply that all fields of study are equal. The reviewer maintains: "It is simplistic to compare outcomes for graduates of limited enrolment professional degree programs with bachelor's programs in arts and science without even mentioning the high degree of selection that has already taken place." But readers who do not realize that there are differences in effort, academic requirements, and investment of time and money, between a master's or Ph.D. program and a one- or two-year college diploma, should not bother with this study. The criticism just reinforces the study's major point: there is a mismatch between supply and demand. Graduates of 
fields where enrolment is limited, particularly professionally-oriented programs, are doing better than graduates of less job-related programs ("Some Thoughts on the Numbers Game," page 51). It is true that, except for medicine, we did not mention entrance requirements and other restrictions, but this study deals with labour market outcomes two years after graduation, not entrance requirements of different programs.

4. The reviewer finds our choice of data selective, but she is no less discriminating in her use of figures. For example, she notes: " $10 \%$ of philosophy B.A.'s earned more than $\$ 24,100$, while $10 \%$ of business and commerce B.A.'s earned more than $\$ 20,400$." But she should have mentioned the other end of the scale: the average salary for bachelor's philosophy graduates was $\$ 12,800$, and the bottom $10 \%$ were earning less than $\$ 7,000$, while the business and commerce average was $\$ 14,900$, and the lowest $10 \%$ earned less than $\$ 11,100$.

5. The following statement is considered unjustified: "Thus, the message of most graduates after two years of coping with the work world is plain: at universities as well as in colleges they want job-related programs that match the needs of the labour market." (page 153)

But $80.8 \%$ of university and $89.9 \%$ of college graduates said that the relationship of their job to their field of study is important (item VIII-2, Tables 6 and 7 , pages 62 and 66). If we cannot rely on the judgment of university and college graduates, that is not much to the credit of our postsecondary institutions.

Furthermore, we specify programs that "match the needs of the labour market." This means that students generally want not only job-oriented education, but they want to be trained in fields that are in demand or at least do not have significant oversupply. They want work that requires their qualifications. That they take other sorts of jobs, because they have no choice, is another matter. Surely most graduates in an unrelated job with a low salary would accept a position that matched their qualifications in content and salary.

\section{Regrets and Plans for Future Postsecondary Enrolment}

Considerable space is devoted to the graduates' regrets about their choice of program, and the related issue, plans for postsecondary enrolment. It is observed that on the rank order table the average for bachelor's degree recipients is $25.5 \%$ regretting their choice of field. The critique then goes on: "Although some arts and science bachelor's fields exceed this, a number of vocational diploma fields are as high or higher".

In reality, it was rather more than some fields that produced a higher than average proportion of bachelor's degree graduates who subsequently regretted their choice of program. These fields together accounted for about $50 \%$ of the bachelor's degree recipients: physical education, geology, agriculture and biological science, political science, English, economics, geography, miscellaneous social sciences, chemistry, psychology, history, biology, sociology, and physics.

of course, many college graduates regretted their choice, too. Although 
their education was job-oriented, this could be because their skills were not in great demand when they graduated. Our comments on college business graduates state:

Yet far fewer than average had jobs directly related to their program, and their $40 \%$ underemployment rate was one of the highest for college graduates. More than $50 \%$ of those employed full-time, particularly women, had clerical or sales jobs for which employers traditionally required only secondary education. (page 297)

We also observe:

Unfortunately, the oversupply in quite a few disciplines and an uneven geographic distribution that upsets the balance between supply and demand affect national totals. The result is a less favourable employment outcome for college graduates as a whole than the nature of their training would suggest. . . With a large number of applicants, employers may have hired the graduates for routine clerical or sales job that years ago would have been filled by people with less education. (page 68)

I accept the criticism of the section on plans for future postsecondary enrolment We failed to emphasize in enough detail the reasons why students may undertake further postsecondary education. This question deserves more attention, but it is an issue that was not probed in the survey (this is a weakness of the survey). Nonetheless, whatever their particular motivation, eight of 10 graduates contemplating a return said: "For career prospects."

Overall, we found that a considerably larger percentage of graduates who said they were underemployed or working in not directly related jobs planned further postsecondary study than those who were not underemployed or were working in a directly related job. Also, the majority who regretted their choice of field were not in a directly related job, were underemployed, and had lower than average salaries. We never state that only general degree-holders wanted to go back. What we say is that graduates who did not fare well on the labour market "wanted to take more job-related and thus, more rewarding programs."

Several cross-tabulations, which do not appear in Job Market Reality, confirm the preceding remarks. For example, Table 1 shows that as their salary rises, the percentage of graduates planning to return to school to improve their career prospects drops steadily. Table 2 indicates that graduates whose jobs were not related to their field were most likely to contemplate a return to postsecondary study. A breakdown of graduates by field of study in Table 3 reveals that the percentage planning further education was higher among those who regretted their choice of field than among those without such regrets. Cross-tabulations of other variables would produce similar results.

The belief seems to be that we are advocating community college training instead of university. The reviewer says that data from an earlier study on the graduates' retrospective preferences are mentioned only briefly in Job Market 
76 Zoltan Zsigmond

TABLE 1

University graduates planning further education, by salary and motivation

\begin{tabular}{|c|c|c|c|c|c|c|}
\hline \multicolumn{2}{|c|}{$<\$ 7,000$} & $\begin{array}{l}\$ 7,000- \\
\$ 10,000\end{array}$ & $\begin{array}{l}\$ 10,000- \\
\$ 14,000\end{array}$ & $\begin{array}{l}\$ 14,000- \\
\$ 18,000\end{array}$ & $\begin{array}{l}\$ 18,000- \\
\$ 24,000\end{array}$ & $\$ 24,000+$ \\
\hline $\begin{array}{l}\text { career reasons } \\
\text { other reasons } \\
\text { no plans }\end{array}$ & $\begin{array}{r}63 \\
8 \\
29 \\
\end{array}$ & $\begin{array}{l}51 \\
10 \\
39 \\
\end{array}$ & $\begin{array}{r}48 \\
7 \\
45 \\
\end{array}$ & $\begin{array}{r}45 \\
9 \\
46 \\
\end{array}$ & $\begin{array}{l}38 \\
10 \\
52 \\
\end{array}$ & $\begin{array}{l}28 \\
14 \\
58 \\
\end{array}$ \\
\hline & 100 & 100 & 100 & 100 & 100 & 100 \\
\hline
\end{tabular}

TABLE 2

Un1versity graduates planning further education, by relationship of job to fleld of study and motivation

Related Partly related Not related

career reasons

other reasons

no plans

\begin{tabular}{rr}
39 & 46 \\
8 & 11 \\
53 & 43 \\
\hline 100 & 100
\end{tabular}

TABLE 3

Graduates working full-time and planning further postsecondary study for career prospects, by satisfaction with cholce of field

Percentage of graduates planning further study

$\begin{array}{ll}\text { Regret choice } & \text { Do not regret } \\ \text { of fleld } & \text { choice of field }\end{array}$

College graduates

University graduates

General (no specialization)

Humanties

Mathematics and physical sciences

Social sciences

$54-31$

Agriculture and blological sciences

Business and comerce

Fine and applied arts 
Reality. However, in the section where graduates who regretted their choice of field are discussed, we observe:

With further analysis of the data, additional findings emerge about their regrets:

1. Very few were sorry they had acquired postsecondary education; disappointment focused mainly on the specific field of study.

2. Most university graduates would still have chosen university, but a different program.

3. Most college graduates wished they had gone to university. (page 153)

It is suggested that we should have checked whether the students actually did enrol in the next two years. Apart from another survey, there is no way to do this. But that is beside the point. We do not say that the graduates "did" or "would" enrol. What we say is: "About $45 \%$ of all graduates said they intended to enrol in postsecondary institutions within two years." A better idea of the tenor of our remarks on the issue of further postsecondary education is the following excerpt:

Graduates who did not fare well on the labour market wanted to take more job-oriented and thus more rewarding, programs. These findings have some pertinence for the current debate about the goals of postsecondary (particularly university) education. The conviction of some academics that universities should remain independent of labour market needs conflicts with the recent view that they will have to provide more joboriented programs. Consensus on this issue appears remote. The argument might benefit from the reactions of former students. Results of the 1978 survey consistently show that graduates favoured career-oriented studies. Graduates with disappointing work experiences were not the only ones to feel this way; most of the relatively successful ones considered it important to have a job related to their education.

Confronted with such data, planners and policymakers might consider some questions. For one thing, bearing in mind that many newly hired graduates may be reluctant to leave their jobs for full-time study during a tight economic period, what provisions are postsecondary institutions making for part-time or evening courses in job-related programs? Another point concerns the high cost of postsecondary education. In a sense, taxpayers have to pay twice to educate many students who go back for retraining when they find that their first diploma or degree is no guarantee of early success on the labour market. (page 157)

From the above paragraphs, the reviewer quotes the last two sentences, and then goes on: "This interpretation seems unfair. The data do not prove that plans for further education result only from lack of labour market success". She should 
have also quoted another sentence: "... the authors also hope it may provoke more long-term planning by institutions and governments, in consultation with potential employers to fill gaps in the labour force and reduce youth unemployment and underemployment." (page 38)

We consider "planners and policy makers" to be part of our audience. They include those who are studying labour market demand and debating the role of universities. We are simply suggesting that they listen to former students. After all, more than $80 \%$ of the graduates considered it important to have a job related to their field.

A realistic labour market demand forecast would help institutions as well as postsecondary students make better decisions. Lacking such forecasts, studies like Job Market Reality can serve as the next best alternative by monitoring labour market results for all school leavers. Similar or even more detailed surveys would surely help potential postsecondary students make a better-informed choice of program. A calculation derived from Job Market Reality illustrates the possible cost of a return to university.

Of the 52,923 university graduates working full-time, $24.5 \%$ or 12,966 regretted their choice of program. If they had it to do over again, the majority said they would still have gone to university, but would have taken a different program. More than half $-51 \%$ or 6,600 - said that they intended to enrol within two years to improve their career prospects. Assuming that only a third actually did enrol in a different university program, this would have meant 2,200 students. The average operating cost per full-time equivalent student (FTE) for the four consecutive academic years, 1976-77 to 1979-80, expressed in 1979 dollars, was $\$ 27,100$. Of that amount, taxpayers' expenditures represented $\$ 22,400$. If the number of potential returning students $(2,200)$ is multiplied by the taxpayers' average share of university operating expenditures $(\$ 22,400)$, the result is $\$ 49$ million.

\section{Employment Outcomes by University and College Disciplines and Employment Experience by Occupation}

In these sections, our findings are described quite accurately, but data that do not support the general conclusions are stressed. It is noted: "Some of the comments on the tables do not precisely reflect the data" and "This choice of detail for comment may not indicate any deliberate bias on the part of the authors, but there does appear to be an emphasis on data that show favourable outcomes for job-oriented disciplines." By and large, graduates of such programs were more successful than the large number of humanities, most of the social sciences, and other non-vocational graduates. Exceptions among any type of graduates do not change the general findings.

A good point, however, is made with the observation: "It also seems strange that $33.3 \%$ of bachelor's graduates employed as teachers would perceive themselves underemployed, since throughout Canada the degree is now required in 
order to obtain a teaching certificate." After publication, we realized that underemployment, particularly among those who graduated as part-time students and had many years of working experience, may have been inflated. The reason is that the survey questionnaire asked: "When you were selected for that job, what minimum educational qualifications did your employer specify as a requirement for it?" When some of the older elementary teachers were first hired for their present position, the requirement may have been teachers' college education only. Nevertheless, according to the Canadian Teacher's Federation and the Canadian Education Association, a degree is still not requisite for elementary teaching in some provinces. And in the 1976-77 academic year, when most 1976 graduates would have started, a degree was mandatory for elementary teaching only in P.E.I., Ontario, and Alberta. This technical problem may have inflated the university underemployment data.

On the other hand, we may have minimized underemployment by not differentiating between master's and Ph.D. graduates and bachelor's degree recipients. About $64 \%$ of master's degree-holders accepted a job requiring only a bachelor's degree. Consequently, reported underemployment rates for those with graduate degrees may be deflated.

The high rate of underemployment in the senior and middle management ranks may be because the group, as defined by the C.C.D.O. (Canadian Classification Dictionary of Occupations) may be too broad at that level of aggregation. It includes everyone from corporate executives to owners of shoe repair shops.

The reviewer complains that we stressed the high level of dissatisfaction in certain occupations or industry groups with a relatively small number of graduates: "Although numbers are given in the tables, the problems of these few graduates are not placed in the larger context of suitable and successful employment for most graduates." In the part referred to we are commenting on a particular occupation or industry. Overall results for 113 fields of study are shown in the section on job satisfaction for all graduates. We state:

Only $12 \%$, a relatively small group, said they were not satisfied with their jobs, and there was virtually no difference between college and university graduates. Most satisfied were master's and Ph.D. graduates, with $90 \%$ liking their job. The average at other levels was a few percentage points lower.

The survey did not go into reasons for graduates' discontent. Given the relative frequency of some of the other negative indicators, such as underemployment, job dissatisfaction might be expected to have been more prevalent than it was. Apparently most graduates accepted the realities of the job market and could put up with being underemployed. Perhaps they felt that any job was better than none. They may also have recognized that as newcomers to the labour force they still had much ground to cover in gaining the work experience so essential to career advancement. (page 150)

The critique ends with a seven-point summary of why the reviewer objects to 
use of Job Market Reality by students, parents or even guidance counsellors. In my response I have attempted to show that much of what she said is missing is actually in the publication, though not perhaps exactly where she would like to see it. At the outset, I acknowledged that the layout is inconvenient. I accept the suggestion that future surveys seek more clarification of the softer data.

I must make one final point. The reviewer says: "The report repeatedly asserts that job-related education ensures labour market success." On the contrary, nowhere in the report do we say that any type of program ensures success. To make such guarantees would be indefensible. The statistics reveal that some graduates had a better labour force outcome than others, but this does not mean that anyone following such a program is ensured of success. Near the beginning of the study, we try to put the findings in context:

Since present enrolment points to a continuing increase of postsecondary graduates, competition for jobs requiring postsecondary education will probably persist.

As readers examine the survey results, it is important to remember that the goals of postsecondary education are more than simply meeting the needs of the job market. $A$ discussion of the multiple roles of postsecondary institutions is beyond the scope of this study, which deals only with the labour market success of graduates. With this in mind, the authors' aim is only to provide a realistic picture of outcomes for different fields, while cautioning that students and new graduates should not always expect instant success, whatever the field. (page 52)

I conclude with a short story:

Just after publication, I talked to a university official who had taken a dim view of the report. When I asked what was wrong with it, the answer was: "It depends on how you ask me. From a private citizen's perspective, there is really not much to criticize. It is high time someone got to the real issues. But in my official capacity, I have to object." I think that says it all. 